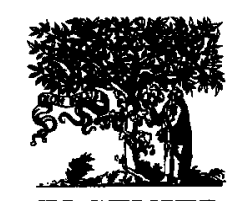

ELSEVIER

International Journal of Mass Spectrometry and Ion Processes 137 (1994) 43-54

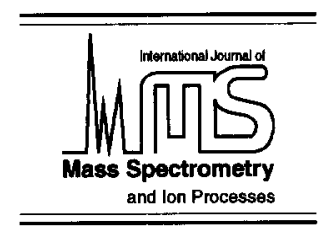

\title{
Gas-phase reactions of chloro- and bromoanisoles with methyl- and dimethylamine via radical cations
}

\author{
Detlef Thölmann, Susanne Hamann, Hans-Friedrich Grützmacher* \\ Fakultät für Chemie der Universität Bielefeld, Postfach 1001 31,33501 Bielefeld, Germany
}

Received 24 January 1994; accepted 14 June 1994

\begin{abstract}
Ionic gas-phase reactions of chloro- and bromoanisoles with $\mathrm{CH}_{3} \mathrm{NH}_{2}$ and $\left(\mathrm{CH}_{3}\right)_{2} \mathrm{NH}$ via radical cations were investigated by FT-ICR spectrometry using an external ion source. Protonated $N$-methylanisidines are formed quantitatively from bromoanisole radical cations with $\mathrm{CH}_{3} \mathrm{NH}_{2}$ by ipso substitution of the bromo atom. The analogous reaction of chloroanisole radical cations produce a mixture of protonated and radical cationic $N$-methylanisidines, the latter ions arising by loss of $\mathrm{HCl}$ from the addition complex and corresponding also to ipso substitution products. The branching ratio of product ions and the reaction efficiencies depend on the structure of the haloanisole radical cations, the efficiencies ranging from $1.3 \%$ to $24 \%$. The observed dependence of the reactivity on the substitution pattern is in good agreement with earlier results of the reactions of dihalobenzene radical cations with $\mathrm{NH}_{3}$ and shows that all substitution reactions proceed by the same multistep mechanism in which the addition of the amine to the aromatic radical cation in the collision complex is rate determining. The reactions of $\left(\mathrm{CH}_{3}\right)_{2} \mathrm{NH}^{++}$with neutral bromoanisoles in the ICR cell produce protonated $N, N$-dimethylanisidines besides bromoanisole radical cations by charge exchange. Chloroanisoles produce with $\left(\mathrm{CH}_{3}\right)_{2} \mathrm{NH}^{+}$additionally $N, N$-dimethylanisidine radical cations by loss of $\mathrm{HCl}$. Deuterium labelling experiments reveal that the $\mathrm{H}$ atom eliminated with $\mathrm{HCl}$ originates from the amino group. The kinetic behaviour of both substitution processes indicates that branching between loss of $\mathrm{Cl}$ and $\mathrm{HCl}$ occurs after the rate determining addition step in a chemically activated intermediate. Competition of loss of $\mathrm{Cl}$ and by elimination of $\mathrm{HCl}$ is observed only for reactions of low reaction efficiencies and is apparently controlled by the excess energy of the excited intermediate adduct.
\end{abstract}

Keywords: FT-ICR; Gas phase substitution; Haloanisoles; Ion/molecule reaction; Radical cations

\section{Introduction}

In previous reports $[1,2]$ the gas phase substitution reactions of halobenzenes with $\mathrm{NH}_{3}$, $\mathrm{CH}_{3} \mathrm{NH}_{2}$, and $\left(\mathrm{CH}_{3}\right)_{2} \mathrm{NH}$ via radical cations were discussed. The reaction (1) of halobenzene and dihalobenzene radical cations with

\footnotetext{
* Corresponding author.
}

$\mathrm{NH}_{3}$ or $\mathrm{CH}_{3} \mathrm{NH}_{2}$ corresponds to a nucleophilic ipso substitution of an activated halobenzene [3]. These reactions show a distinct dependence of the individual reaction rates on the differences of the ionization energies (IE) of the amine and the arene as well as on the substitution pattern of the dihalobenzene. These results were explained by an additionelimination mechanism and interpreted by the 
use of a modified configuration mixing model of Shaik and Pross [4].

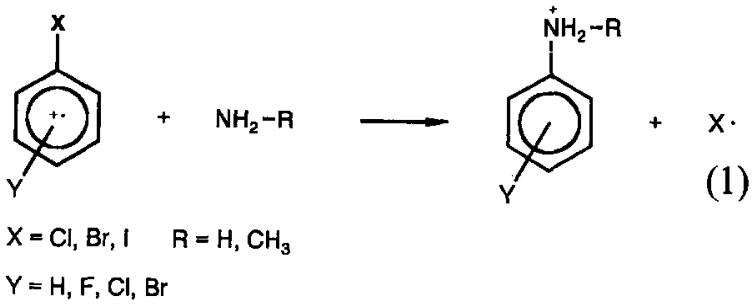

For a further investigation of the mechanism(s) of the aromatic substitution via radical cations in the gas phase, the haloanisoles with a substantially lower IE [5] are used in this study. The IE difference $(\Delta \mathrm{IE})$ between the haloanisoles and $\mathrm{CH}_{3} \mathrm{NH}_{2}$ is similar to that of dihalobenzenes and $\mathrm{NH}_{3}$. Hence, the reactions of chloro- and bromoanisole radical cations with amines are expected to exhibit a close analogy with the corresponding reactions of dihalobenzene radical cations and $\mathrm{NH}_{3}$ and provide a useful additional test for the mechanistic effects discussed previously.

The electrophilic ipso substitution reaction of neutral halobenzenes by amine radical cations in the gas phase was also studied (reaction (2)) [2]. The configuration mixing model [4] predicts a small activation barrier for the addition step of this process.

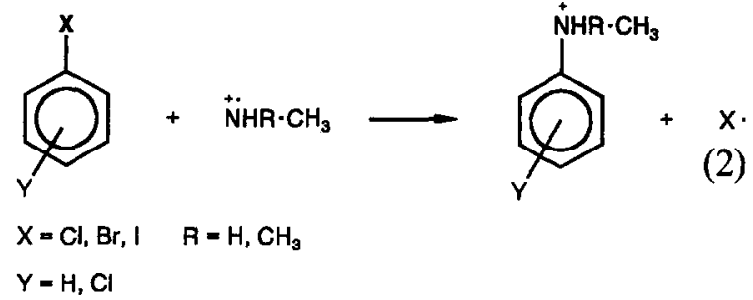

The reactions of $\mathrm{CH}_{3} \mathrm{NH}_{2}^{+}$ions with the halobenzenes proceed with nearly unit efficiency; the corresponding reactions of $\left(\mathrm{CH}_{3}\right)_{2} \mathrm{NH}^{+}$radical cations are distinctly less efficient, however [2]. The slow reactions of $\left(\mathrm{CH}_{3}\right)_{2} \mathrm{NH}^{+}$radical cation were attributed to an additional rearrangement step besides addition and elimination steps. The initial addition of the amine radical cation to the aromatic ring is energetically favored at the ortho- or para-position relative to the leaving substituent. Hence, migration of the amino moiety by consecutive 1,2-shifts around the aromatic ring has to take place to arrive eventually at the reactive ipso-adduct. The rearrangement of the amino group by this "ring walk" is very likely associated with an activation energy and should depend on the presence of other substituents at the aromatic ring. Eventually this rearrangement may become the rate determining step for less exothermic reactions. To corroborate these explanations and to test the influence of other parameters, the reactions of $\left(\mathrm{CH}_{3}\right)_{2} \mathrm{NH}^{+}$radical cations with neutral

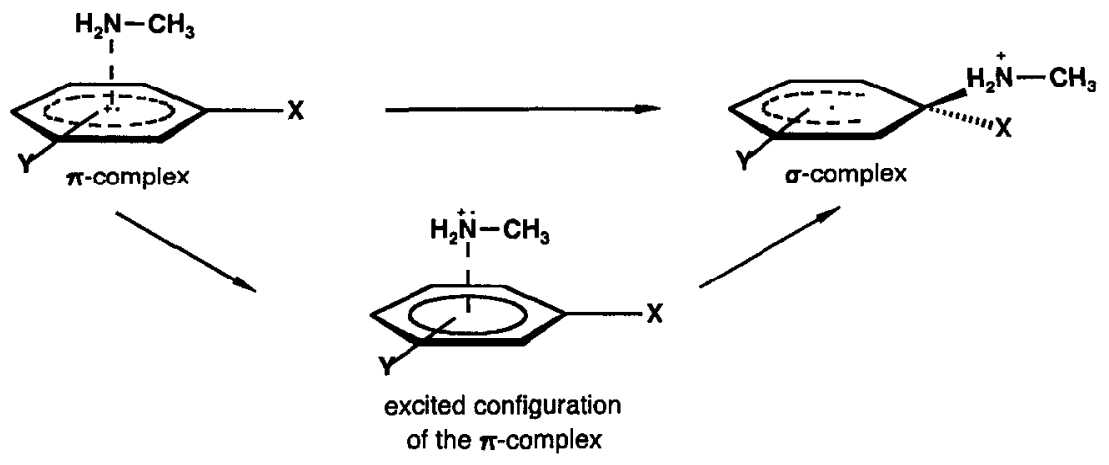

Scheme 1 . 
chloro- and bromoanisoles are investigated in the second part of this work.

\section{Experimental section}

The bromoanisoles are commercially available and were used without further purification; chloroanisoles were prepared from the corresponding chlorophenoles by $O$ methylation with methyl $p$-toluenesulfonate [6]. $N$-methyl anisidines were prepared by reaction of the corresponding anisidines with trimethyl orthoformate and subsequent acidic amide cleavage of the $N$-methyl- $N$-formyl anisidines [7]. The purity of the haloanisoles and the anisidines was better than $99 \%$ (by gas chromatography) with the exception of 3-bromoanisole which contained $1-2 \%$ of 4-bromoanisole. Methylamine $(97 \%)$ and dimethylamine $(99 \%)$ were obtained from Merck. Deuterated chloroanisoles were prepared by stirring the chloroanisoles with $74 \%$ to $95 \% \mathrm{D}_{2} \mathrm{SO}_{4}$ in $\mathrm{D}_{2} \mathrm{O}$ at $100^{\circ} \mathrm{C}$.

FT-ICR measurements were performed with a Spectrospin CMS 47X FT-ICR spectrometer [8] equipped with a $4.7 \mathrm{~T}$ superconducting magnet, a $24 \mathrm{bit} / 128 \mathrm{k}$-word ASPECT $3000 \mathrm{com}$ puter, a cylindrical cell of $6 \mathrm{~cm}$ diameter and $6 \mathrm{~cm}$ length, and an external ion source [9]. The radical ions were generated in the external ion source by electron impact $(16-20 \mathrm{eV})$ from the haloanisoles or amines, and were transferred into the ICR cell. The trapping voltages at the front and back trapping plates were ca. $1 \mathrm{~V}$, the other plates were kept at $0 \pm 0.1 \mathrm{~V}$. Selection of the reacting radical cations was achieved by broad band (frequency sweep) ejection of fragment ions of $m / z>50$. The excitation voltage was attenuated by an attenuator of 6 , corresponding to $88 V_{\mathrm{p}-\mathrm{p}}$. Ions of masses below $\mathrm{m} / \mathrm{z} 50$ and the isotopomers of the aromatic radical cations containing ${ }^{13} \mathrm{C},{ }^{37} \mathrm{Cl}$, and ${ }^{81} \mathrm{Br}$ isotopes were ejected by fixed frequency $\mathrm{rf}$ pulses ("single shots") of $14 V_{\text {p-p }}$ and of $1.5 \mathrm{~ms}$ duration. Special care was taken to remove any kinetic energy from the selected radical cations. The collisional "cooling" of the isolated ions was achieved by a short pulse of argon admitted to the ICR cell by a pulsed valve (opening time $15 \mathrm{~ms}$ ) prior to the reaction. After a delay time of $500 \mathrm{~ms}$ to remove the argon from the cell, any fragment ions formed were ejected by "single shots" $\left(14 V_{\mathrm{p}-\mathrm{p}}\right.$, $1.5 \mathrm{~ms})$. This ejection method diminishes the probability of re-excitation of the reacting ions by the ejection procedure.

The neutral reactant gas was continuously introduced from a reservoir into the ICR cell by a leak valve at a constant pressure of $2 \times 10^{-8}$ to $7 \times 10^{-7}$ mbar. The purity of the neutral reactant gas phase in the ICR cell was controlled by a mass spectrum obtained with the internal ionization mode of the spectrometer. The pressure readings of the ionization gauge attached to the vacuum envelope near the diffusion pump of the ICR cell were calibrated by measuring the rates of the reactions $\mathrm{CH}_{4}^{+}+\mathrm{CH}_{4} \quad\left(k=1.5 \times 10^{-9} \mathrm{~cm}^{3} \mathrm{~s}^{-1}\right.$ [10] $), \mathrm{NH}_{3}^{+}+\mathrm{NH}_{3} \quad\left(k=2.2 \times 10^{-9} \mathrm{~cm}^{3} \mathrm{~s}^{-1}\right.$ [11]), and $\mathrm{CH}_{3} \mathrm{NH}_{2}^{+}+\mathrm{CH}_{3} \mathrm{NH}_{2} \quad(k=1.8 \times$ $10^{-9} \mathrm{~cm}^{3} \mathrm{~s}^{-1}$ [12]). The relative experimental calibration factors of $\mathrm{CH}_{4}, \mathrm{NH}_{3}$, and $\mathrm{CH}_{3} \mathrm{NH}_{2}$ correspond to the known relative sensitivities of the ionization gauge toward these gases [13]. Therefore, the calibration factors of dimethylamine and the aromatic compounds were calculated from the corresponding ion gauge sensitivities by a standard literature procedure [13].

FT-ICR spectra were obtained with $32 \mathrm{~K}$ or $64 \mathrm{~K}$ data for about 20 different reaction times, covering up to $95 \%$ conversion of the reacting ions. After exponential multiplication and Fourier transformation, the ion intensities of the magnitude spectra were normalized with respect to the sum of ions formed after the corresponding reaction time. Pseudo-first order reaction kinetics were obtained from the exponential decay of the signal of the reacting ions. 
To ensure correct measurements of the true ion abundances the variation of the sum of the absolute ion intensities with reaction time was examined and compared with the variation of the intensity of trapped unreactive ions at the corresponding delay times ("trapping characteristics"). This method allows a correction of erroneous ion abundance measurements as described in detail elsewhere [8]. If more than one product ion is formed in considerable amounts, this method is not very exact, and the determination of the branching ratio in competitive substitutions of two substituents may be less accurate. In these cases special care was taken to avoid "picket-fence" errors [14] by a suitable gaussian multiplication and use of $64 \mathrm{~K}$ data.

Collision activation (CA) spectra of ions formed by ion/molecule reactions in the ICR cell were obtained by rf excitation of the relevant ions and collision with argon. To avoid reactions of the fragment ions with the reactant gas $\mathrm{CH}_{3} \mathrm{NH}_{2}$, the amine was introduced by a pulsed valve and pumped off for 10 to $15 \mathrm{~s}$ after a reaction delay. In spite of this long pumping time some $\mathrm{CH}_{3} \mathrm{NH}_{2}$ remains in the ICR cell, giving rise to the formation of $\mathrm{CH}_{3} \mathrm{NH}_{3}^{+}$ ions by the reaction with fragment ions formed during the CA experiment. The center-of-mass energy $E_{\mathrm{cm}}$ of the collision was adjusted to $17 \mathrm{eV}$ by applying the proper excitation pulse for the molecular ions to the FT-ICR cell. The kinetic energy of the ions after rf excitation was obtained by the following equation [15]:

$$
E_{k i n}=\beta^{2} \frac{V_{\mathrm{p}-\mathrm{p}}^{2} q^{2} t^{2}}{8 m d^{2}}
$$

The parameter $\beta$ is a factor depending on the geometry of the ICR cell. For a cylindrical cell of length $6 \mathrm{~cm}$ and diameter $d=6 \mathrm{~cm}$, $\beta=0.809$ is obtained [15]. $V_{\mathrm{p}-\mathrm{p}}$ is the peakto-peak voltage of the rf-pulse and $t$ the corresponding time. Mass and charge of the ion are given by $m$ and $q$.

\section{Results}

Bromoanisole radical cations react with $\mathrm{CH}_{3} \mathrm{NH}_{2}$ by substitution of the $\mathrm{Br}$ atom and formation of protonated $\mathrm{N}$-methyl anisidines (reaction 3a), but chloroanisole radical cations yield additionally $N$-methyl anisidine radical cations by elimination of $\mathrm{HCl}$ (reaction $3 b$ ). The total reaction efficiencies depend on the substitution pattern of the haloanisole radical cation (Table 1). The reactivity is by far highest for the ortho isomers and lowest for the para isomers. Qualitatively, this reactivity order corresponds to that found for reactions (1) of the dihalobenzene radical cations with ammonia. However, the reactions of meta haloanisoles radical ions are comparatively slow. For example, the substitution efficiencies of ortho- meta-, and para-chloroanisole by $\mathrm{CH}_{3} \mathrm{NH}_{2}$ are $19 \%, 3.1 \%$, and $1.3 \%$, while for the analogous reactions of ortho-, meta-, and para-chlorofluoro-benzene radical cations with $\mathrm{NH}_{3}[1]$ these efficiencies are $12 \%, 8.4 \%$, and $2.3 \%$, respectively. Similarly, the reactions of isomeric bromoanisole radical cations with $\mathrm{CH}_{3} \mathrm{NH}_{2}$ exhibit efficiencies of $24 \%, 4.9 \%$, and $4.3 \%$ compared with efficiencies of $14 \%, 7.5 \%$, $2.8 \%$ for the reactions of the bromofluorobenzene radical cations with $\mathrm{NH}_{3}$ [1]. A substitution by loss of $\mathrm{HCl}$ from haloarene radical

Table 1

Rates constants ( $k$ ) and efficiencies (eff.) for the reactions (3) of chloro- and bromoanisole radical cations with $\mathrm{CH}_{3} \mathrm{NH}_{2}$

\begin{tabular}{lccccc}
\hline Radical cation of & $k^{\mathrm{a}}$ & $\begin{array}{l}\mathrm{Eff}^{\mathrm{b}} \\
(\%)\end{array}$ & $k_{\mathrm{Cl}} / k_{\mathrm{HCl}}^{\mathrm{c}}$ & $\begin{array}{l}\mathrm{Eff.}_{\mathrm{Cl}}^{\mathrm{b}, \mathrm{d}} \\
(\%)\end{array}$ & $\begin{array}{l}\mathrm{Eff}_{\mathrm{HCl}}^{\mathrm{b}, \mathrm{e}} \\
(\%)\end{array}$ \\
\hline o-Chloroanisole & 31 & 19 & 10 & 17 & 1.7 \\
$m$-Chloroanisole & 5.0 & 3.1 & 0.15 & 0.4 & 2.7 \\
$p$-Chloroanisole & 2.1 & 1.3 & 0.09 & 0.1 & 1.2 \\
$o$-Bromoanisole & 37 & 24 & & & \\
$m$-Bromoanisole & 7.7 & 4.9 & & & \\
$p$-Bromoanisole & 6.8 & 4.3 & & & \\
\hline
\end{tabular}

${ }^{\mathrm{a}} \times 10^{-11} \mathrm{~cm}^{3}$ molecule ${ }^{-1} \mathrm{~s}^{-1} .{ }^{\mathrm{b}}$ Efficiency $=k / k_{\text {cap }} ;$ capture rate, $k_{\text {cap }}$, according to parametrized trajectory calculations [20]. ${ }^{c} k_{\mathrm{Cl}} / k_{\mathrm{HCl}}=$ branching ratio of reactions (3a) and (3b). ${ }^{\mathrm{d}}$ Reaction (3a). ${ }^{\mathrm{e}}$ Reaction (3b). 


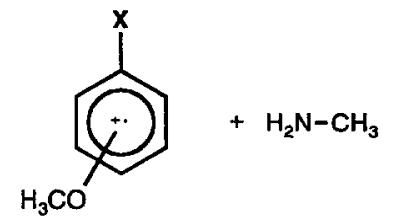

$$
\mathrm{X}=\mathrm{Cl}, \mathrm{Br}
$$

cations has previously been observed only for chloroiodobenzene radical cations [1], which are not very reactive towards $\mathrm{NH}_{3}$ because of their low IE. A low IE is also typical of haloanisoles, and the branching ratios for the loss of $\mathrm{Cl}$ and $\mathrm{HCl}$ (reactions (3a) and (3b)) from these ions are shown in Table 1 . The efficiency of reaction ( $3 b)$ is small for all three isomers and not very different, so the variation of the total reaction efficiencies is mainly due to different rates of reaction (3a).

The elemental composition of the product ions of reactions (3a) and (3b) was confirmed by high resolution $\left(m / \Delta m>10^{5}\right)$ FT-ICR mass spectrometry. Reaction ( $3 a$ ) has previously been shown to correspond to an ipso-substitution for dihalobenzenes $[1,2,16]$, and this is also assumed for the haloanisoles. The structures of the substitution products of reaction ( $3 b$ ) were investigated by collision induced decomposition (CID) in the FT-ICR cell by comparison with reference CA spectra of the molecular ions $\mathrm{C}_{8} \mathrm{H}_{11} \mathrm{NO}^{+}, m / z$ 137, of authentic $N$ methyl anisidines prepared by $20 \mathrm{eV}$ EI ionization and analysed by CID under the same conditions. Several experimental factors may influence the excitation efficiency in FT-ICR spectromety [17], but under the conditions used the actual center-of-mass energies are nearly identical for all CA spectra. However, the CA spectra of the substitution products were measured with a background of $\mathrm{CH}_{3} \mathrm{NH}_{2}$, which could not be removed completely from

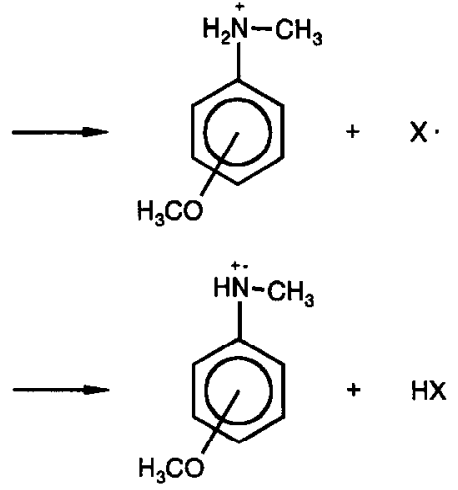

the ICR cell prior to the CID, and which gave rise to some $\mathrm{CH}_{3} \mathrm{NH}_{3}^{+}$ions. The uncontrolled formation of $\mathrm{CH}_{3} \mathrm{NH}_{3}^{+}$ions gives rise to changes in the relative fragment ion intensities, thus variations may not be as indicative for structural differences as for undisturbed CA spectra. The CA spectra of the product ions $\mathrm{C}_{8} \mathrm{H}_{11} \mathrm{NO}^{+}$and reference ions are listed in Table 2 with the exception of the CA spectrum of the product ions of ortho-chloroanisole radical cations because of their low relative intensity. A comparison of the reference CA spectra of the isomeric $\mathrm{N}$-methyl anisidine radical cations shows that the meta isomer is clearly distinguished by the characteristic fragment ions at $m / z 108, m / z 106$, and $m / z 93$, as well as by the missing ions at $m / z 122$ and $m / z$ 95. The CA spectra of the ortho and para isomers contain ions of identical masses, but with different intensities. Characteristic fragment ions are observed at $m / z 122, m / z 94$, and $m / z$ 77. Neglecting the $\mathrm{CH}_{3} \mathrm{NH}_{3}^{+}$ions, $m / z$ 32 , the CA spectra of the substitution product ions from meta and para chloroanisole radical ions are almost identical to the respective reference CA spectra. It is evident from the abundant ions at $m / z 93, m / z 106$, and $m / z$ 108 , that $N$-methyl meta-anisidine radical cations are formed exclusively by the substitution reaction of meta-chloroanisole radical cations with $\mathrm{CH}_{3} \mathrm{NH}_{2}$. The interpretation of the $\mathrm{CA}$ spectrum of the $\mathrm{C}_{8} \mathrm{H}_{11} \mathrm{NO}^{+}$product ions of para-chloroanisole is not as straightforward. 
<smiles>[2H]c1c(Cl)c([2H])c(OC)c([2H])c1[18NH2+]NC</smiles>

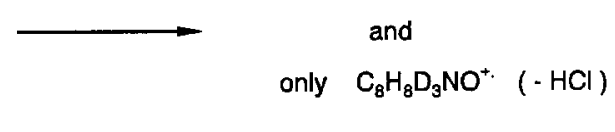<smiles>[2H]c1c([2H])c(OC)c([2H])c([2H])c1Cl</smiles>

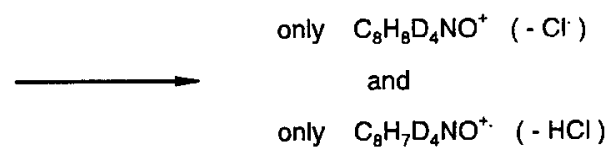

Scheme 2.

However, the structure of $N$-methyl para-anisidine can be assigned reliably by the high relative abundance $(28.9 \%)$ of the $\left[\mathrm{M}-\mathrm{CH}_{3}\right]^{+}$ fragment ions, $m / z 122$, and the low intensity of the ions $m / z 77$ (below the detection limit). Therefore, the aromatic substitution by loss of $\mathrm{HCl}$ corresponds also to an ipso-substitution.

In order to settle the origin of the $\mathrm{H}$ atom eliminated with $\mathrm{HCl}$ the substitution reactions

Table 2

CA spectra of $\mathrm{C}_{8} \mathrm{H}_{11} \mathrm{NO}^{+}$ions, $m / z 137$, formed by reaction of chloroanisole radical cations with $\mathrm{CH}_{3} \mathrm{NH}_{2}$ and of reference ions from IE $(20 \mathrm{eV})$ of $N$-methyl anisidines

\begin{tabular}{lccccc}
\hline$m / z$ & \multicolumn{2}{c}{$\begin{array}{c}\text { reaction } \\
\text { products }\end{array}$} & \multicolumn{3}{c}{ molecular ions of } \\
& $\begin{array}{c}\text { m } / z \\
\text { meta }\end{array}$ & $137^{\mathrm{a}}$ & \multicolumn{3}{c}{$\begin{array}{c}\text { anisidines } \\
\text { and }\end{array}$} \\
& para & ortho & meta & para \\
\hline $137\left(\mathrm{M}^{\prime}\right)$ & 4.5 & 3.5 & 1.5 & 4.7 & 2.5 \\
$136[\mathrm{M}-\mathrm{H}]^{+}$ & 1.8 & - & - & 6.3 & - \\
$122\left[\mathrm{M}-\mathrm{CH}_{3}\right]^{+}$ & - & 28.9 & 17.9 & - & 56.5 \\
$108\left[\mathrm{M}-\mathrm{CHO}^{+}\right.$ & 13.1 & - & - & 25.0 & - \\
$106\left[\mathrm{M}-\mathrm{CH}_{3} \mathrm{O}\right]^{+}$ & 8.7 & - & - & 19.1 & - \\
95 & - & - & 12.7 & - & 2.0 \\
$94\left(\mathrm{C}_{6} \mathrm{H}_{8} \mathrm{~N}\right)$ & - & 21.3 & 41.5 & 1.8 & 28.2 \\
$93\left(\mathrm{C}_{6} \mathrm{H}_{7} \mathrm{~N}\right)$ & 25.6 & 2.5 & - & 30.1 & - \\
77 & 3.7 & - & 10.1 & 5.4 & 2.3 \\
67 & - & 4.3 & 4.9 & - & 3.8 \\
65 & 3.3 & 12.6 & 6.4 & 1.3 & 4.7 \\
$32\left(\mathrm{CH}_{3} \mathrm{NH}_{3}^{+}\right)$ & 25.1 & 17.8 & - & - & - \\
28 & - & - & 5.0 & - & - \\
\hline
\end{tabular}

${ }^{a}$ Rf excitation $9.8 V_{\mathrm{p}-\mathrm{p}}, 140 \mu \mathrm{s}$, ion kinetic energy $120 \mathrm{eV}$ (Eq. (1)).

${ }^{\mathrm{b}} \mathrm{Rf}$ excitation $9.8 V_{\mathrm{p}-\mathrm{p}}, 110 \mu \mathrm{s}$, ion kinetic energy $74 \mathrm{eV}$ (Eq. (1)). of deuterated meta- and para-chloroanisoles with $\mathrm{CH}_{3} \mathrm{NH}_{2}$ were studied. During the reaction of the deuterated chloroanisoles shown in Scheme $2, \mathrm{HCl}$ is eliminated exclusively. Neither the methyl group of the methoxy group nor that of the methylamine is obviously involved in the reaction, because these are intact in the product ions (see CA spectra). In the case of the 2,4,6-trideutero3-chloroanisole loss of $\mathrm{HCl}$ by participation of $\mathrm{H}$ atoms at the aromatic ring would correspond to the exclusive elimination of the remaining $\mathrm{H}$ atom. This would be a very unlikely regiospecificity with respect to participtation of the other D atoms at the aromatic ring and, hence, can be excluded. Therefore, the $\mathrm{H}$ atom eliminated with $\mathrm{HCl}$ originates from the $\mathrm{NH}_{2}$ group of the invading $\mathrm{CH}_{3} \mathrm{NH}_{2}$ molecule.

$\left(\mathrm{CH}_{3}\right)_{2} \mathrm{NH}^{+}$ions react with chloro- and bromoanisoles by the loss of $\mathrm{Cl}$ or $\mathrm{Br}$ (reaction (4a)) and of $\mathrm{HCl}$ (reactions (4b)). However, additionally, charge exchange (4c), proton transfer (4d), and $\mathrm{H}$ atom transfer (4e) are observed. The elemental compositions of the ionic reaction products were confirmed by high resolution, but their structures were not investigated by separate experiments.

The total reaction rates are large (Table 3 ), with the meta-isomers being least reactive. 


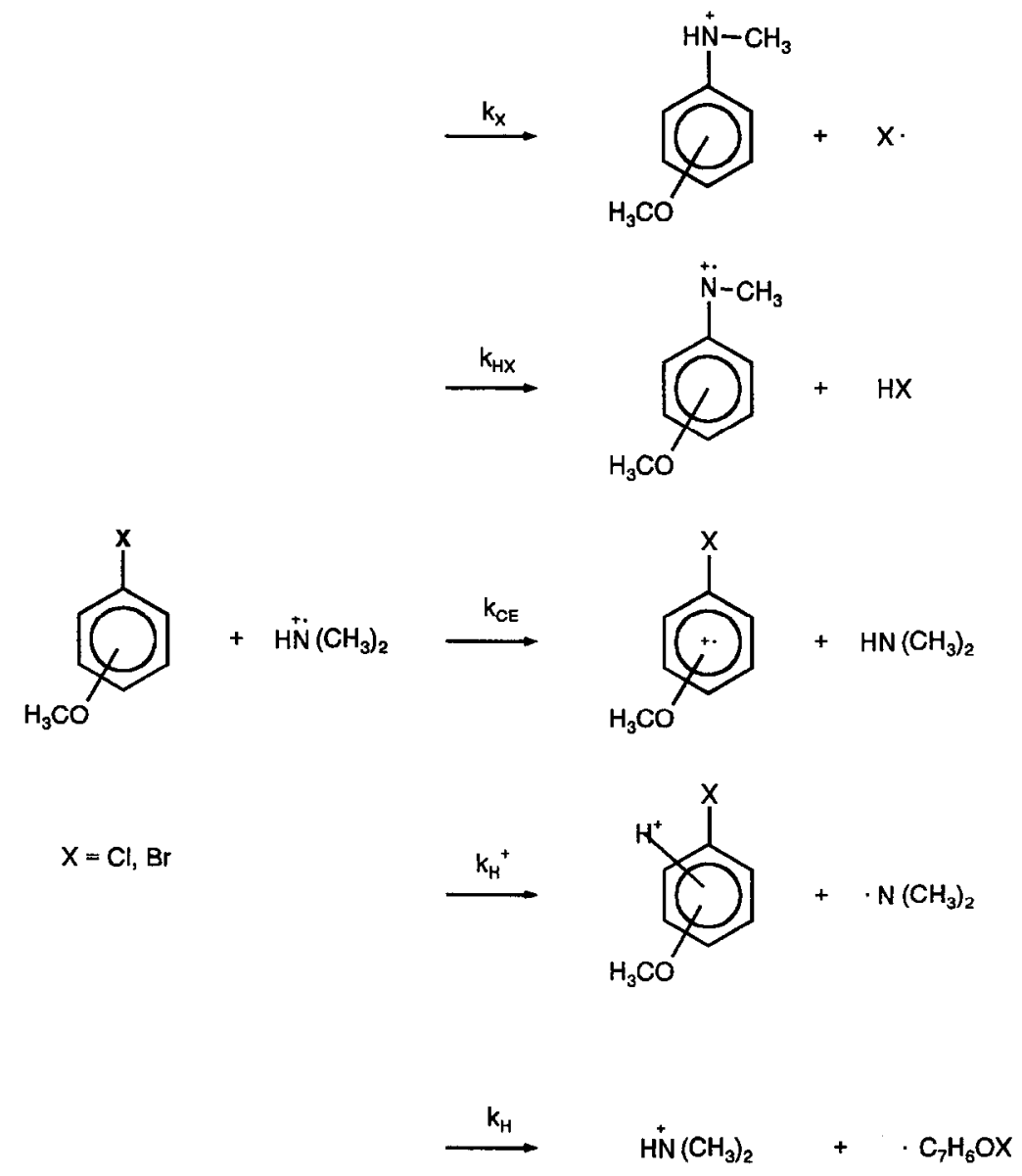

The efficiency of the substitution reaction, eff $f_{\text {sub }}$, is obtained by calculating the branching ratio of all processes involved, as shown in Table 4 for the chloroanisoles. Eff sub $_{\text {sub }}$ parachloroanisole appears to be lower than that of meta-chloroanisole, but this is very likely an artefact due to the especially extensive competition of the charge exchange reaction (4c) in this case. The reason is a considerably lower ionization energy (IE) (para-chloroanisole) of $7.8 \mathrm{eV}$ [5] compared to $\operatorname{IE}\left(\left(\mathrm{CH}_{3}\right)_{2} \mathrm{NH}\right)$ of $8.23 \mathrm{eV}$ [5]. The substitution of $\mathrm{Br}$ of the bromoanisoles by $\left(\mathrm{CH}_{3}\right)_{2} \mathrm{NH}^{+}$is much more straightforward. No loss of $\mathrm{HBr}$ is observed and side reactions are limited to a moderate charge exchange, occurring dominantly again only for para-bromoanisole. It is evident from
Table 3

Rate constants $(k)$ and efficiencies (eff.) for the reactions of chloro- and bromoanisoles with $\left(\mathrm{CH}_{3}\right)_{2} \mathrm{NH}^{+}$ions

\begin{tabular}{llccll}
\hline Compound & $\mathrm{IE}(\mathrm{eV})^{\mathrm{a}}$ & $k^{\mathrm{b}}$ & $\begin{array}{l}\mathrm{Eff}^{\mathrm{c}} \\
(\%)\end{array}$ & $k_{\text {sub }} / k^{\mathrm{d}}$ & $\begin{array}{l}\mathrm{Eff}_{\text {sub }}^{\mathrm{c}} \\
(\%)\end{array}$ \\
\hline$o$-Chloroanisole & 8.4 & 12 & 46 & $0.71 \pm 0.1$ & 33 \\
$\begin{array}{l}m \text {-Chloroanisole } \\
p \text {-Chloroanisole }\end{array}$ & 7.8 & 2.9 & 12 & $0.40 \pm 0.1$ & 4.8 \\
$o$-Bromoanisole & & 9.6 & 39 & $0.07 \pm 0.01$ & 2.7 \\
$m$-Bromoanisole & & 20 & 79 & $0.62 \pm 0.1$ & 49 \\
$p$-Bromoanisole & 8.1 & 26 & 109 & $0.32 \pm 0.1$ & 35 \\
\hline
\end{tabular}

${ }^{a}$ From Ref. [5]. ${ }^{b} \times 10^{-10} \mathrm{~cm}^{3}$ molecule ${ }^{-1} \mathrm{~s}^{-1}$. ${ }^{\mathrm{c}}$ Efficiency $=$ $k / k_{\text {cap }}$; capture rate, $k_{\text {cap }}$, according to parametrized trajectory calculations [20]. ${ }^{d} k_{\text {sub }}=$ rate of the combined substitution reactions (4a) and (4b). 
Table 4

Branching ratios of the reactions ${ }^{\mathrm{a}}$ of chloroanisoles with $\left(\mathrm{CH}_{3}\right)_{2} \mathrm{NH}^{+}$ions

\begin{tabular}{lccccc}
\hline Compound & $\begin{array}{l}k_{\text {sub,Cl}} \\
(\%)\end{array}$ & $\begin{array}{l}k_{\text {sub, HCl }} \\
(\%)\end{array}$ & $\begin{array}{l}k_{\mathrm{CE}} \\
(\%)\end{array}$ & $\begin{array}{l}k_{\mathrm{H}^{+}} \\
(\%)\end{array}$ & $\begin{array}{l}k_{\mathrm{H}} \\
(\%)\end{array}$ \\
\hline o-Chloroanisole & 71 & - & 21 & 8.3 & - \\
$m$-Chloroanisole & 24 & 16 & 8.7 & 4.3 & 47 \\
$p$-Chloroanisole & 5.5 & 1.5 & 83 & 10 & - \\
\hline
\end{tabular}

${ }^{a}$ See reaction (4).

eff.sub in Table 3, that the substitution reaction of neutral meta-bromoanisole by $\left(\mathrm{CH}_{3}\right)_{2} \mathrm{NH}^{+}$ ions is slow compared to the ortho- and paraisomers. This reactivity pattern is different from the ortho $>$ meta $>$ para reactivity order which is valid for the reactions of haloanisole and dihalobenzene radical cations with neutral amines, but matches the pattern found for reactions of $\left(\mathrm{CH}_{3}\right)_{2} \mathrm{NH}^{+}$radical ions with neutral dichlorobenzenes and chloroiodobenzenes [2].

\section{Discussion}

The reactions of the bromoanisole radical cations with $\mathrm{CH}_{3} \mathrm{NH}_{2}$ (Table 5) show an almost perfect analogy with the reactions of dibromobenzene or bromofluorobenzene radi- cal cations with $\mathrm{NH}_{3}$ [1]. The efficiencies of these reactions are fast for small $\Delta I E$ of the reactants while a $\Delta I E \approx 2 \mathrm{eV}$ suppresses any reaction. The reactions of the bromoanisole radical cations $(I E \approx 8.1-8.4 \mathrm{eV}$ [5]) with $\mathrm{CH}_{3} \mathrm{NH}_{2}(I E=8.97 \mathrm{eV}[5])$ have a $\Delta I E$ of $0.8-0.9 \mathrm{eV}$ and are in general slightly faster than the reactions of the bromo-fluorobenzene radical cations with $\mathrm{NH}_{3}$ and a $\Delta I E$ of ca. $1.1 \mathrm{eV}$.

As mentioned before the effect of the aromatic substitution pattern on the reaction efficiencies agrees qualitatively in both series of substitution reactions. It should be emphasized that the variation of the rate of the direct substitution reaction of the haloanisole radical cation and methylamine with the structure of the reactants can be explained convincingly by assuming a mechanism (Scheme 3 ) with a rate determining formation of the $\sigma$-complex $\mathbf{D}$ from the encounter ion/molecule complex $\mathbf{C}$. However, while in the case of the dihalobenzenes radical cations the reactivity order is ortho $>$ meta $\gg$ para, the ortho-bromo- and chloroanisole radical cations exhibit an outstanding reactivity (Table 1 ). This can not be an effect of the dipole moments of the aromatic compounds as discussed before [1]. The

Table 5

Comparison of the reactions of bromoanisole and related bromobenzene radical cations with $\mathrm{CH}_{3} \mathrm{NH}_{2}$ and $\mathrm{NH}_{3}$, respectively

\begin{tabular}{|c|c|c|c|c|}
\hline Reaction & & $\Delta I E(\mathrm{eV})^{\mathrm{a}}$ & $\mu_{\mathrm{D}}(\mathrm{Ar})^{\mathrm{b}}$ & $\begin{array}{l}\text { Eff. }^{c} \\
(\%)\end{array}$ \\
\hline$o$-Bromoanisole ${ }^{+}$ & $+\mathrm{CH}_{3} \mathrm{NH}_{2}$ & $(0.6)^{d}$ & 2.47 & 24 \\
\hline$m$-Bromoanisole ${ }^{+}$ & $+\mathrm{CH}_{3} \mathrm{NH}_{2}$ & & $2.35^{\mathrm{e}}$ & 4.9 \\
\hline$p$-Bromoanisole ${ }^{+}$ & $+\mathrm{CH}_{3} \mathrm{NH}_{2}$ & 0.9 & 2.23 & 4.3 \\
\hline$o$-Dibromobenzene ${ }^{+}$ & $+\mathrm{NH}_{3}$ & 1.4 & 1.90 & 14 \\
\hline$m$-Dibromobenzene ${ }^{+}$ & $+\mathrm{NH}_{3}$ & 1.3 & 1.5 & 4.1 \\
\hline$p$-Dibromobenzene ${ }^{+}$ & $+\mathrm{NH}_{3}$ & 1.5 & 0.0 & 0.91 \\
\hline$o$-Bromofluorobenzene ${ }^{+}$ & $+\mathrm{NH}_{3}$ & $(1.0)^{d}$ & 2.29 & 14 \\
\hline$m$-Bromofluorobenzene ${ }^{+}$ & $+\mathrm{NH}_{3}$ & $(1.0)^{\mathrm{d}}$ & 1.4 & 7.5 \\
\hline$p$-Bromofluorobenzene ${ }^{+}$ & $+\mathrm{NH}_{3}$ & $(1.2)^{\mathrm{d}}$ & 0.5 & 2.8 \\
\hline$p$-Bromoanisole ${ }^{+}$ & $+\mathrm{NH}_{3}$ & 2.1 & 2.23 & n.r. ${ }^{f}$ \\
\hline Bromobenzene $^{+}$ & $+\mathrm{CH}_{3} \mathrm{NH}_{2}$ & 0.0 & 1.7 & 58 \\
\hline
\end{tabular}

${ }^{\mathrm{a}}$ Ref. [5]. ${ }^{\mathrm{b}}$ Ref. [21]. ${ }^{\mathrm{c}}$ efficiency $=k / k_{\text {cap }}$; capture rate, $k_{\text {cap }}$, according to parametrized trajectory calculations [20]. ${ }^{\mathrm{d}}$ The $I E$ of the bromoarenes are unknown, values given correspond to $I E$ of the chloro derivatives [5]. ${ }^{e}$ Estimated from experimental $\mu_{\mathrm{D}}$ of the ortho and para isomers, and from MNDO calculations. ${ }^{f}$ No reaction. ${ }^{8}$ Ref. [2]. 


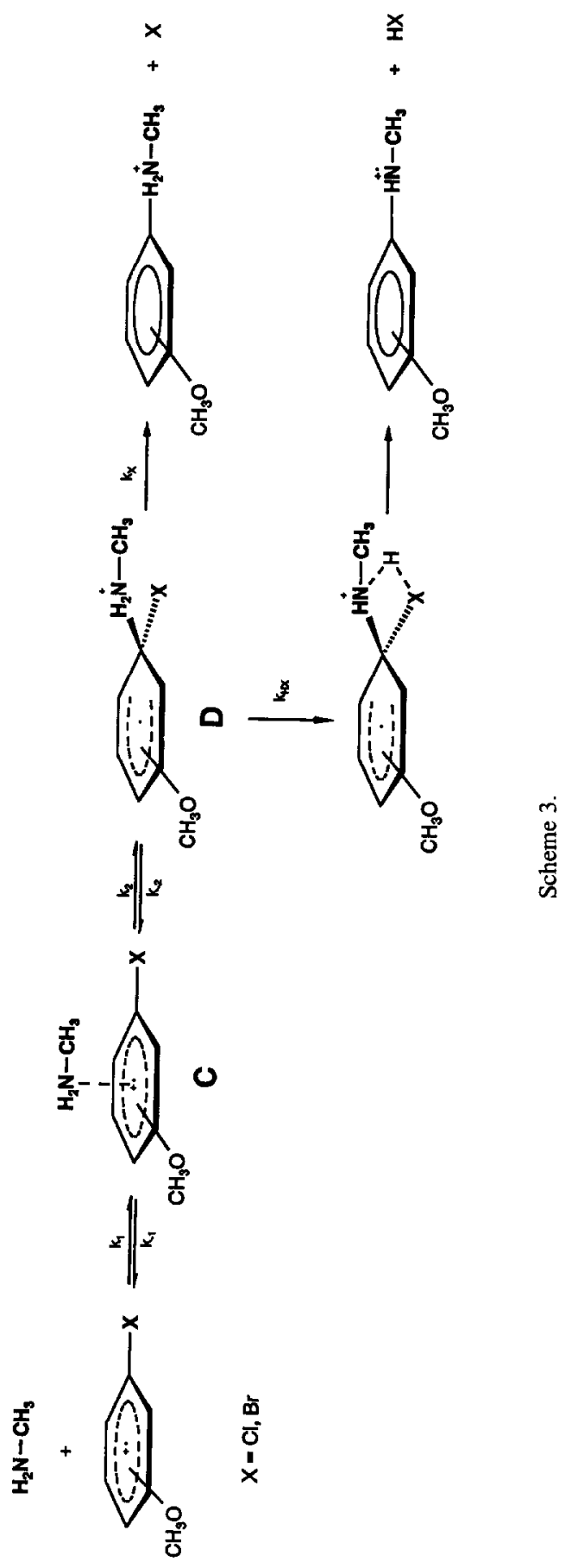




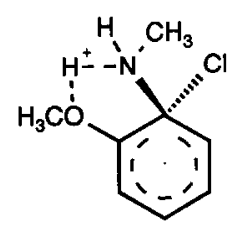

Scheme 4.

isomers of the haloanisoles have very similar dipole moments (Table 5), and only small reactivity differences between these isomers are expected due to an extra stabilization of the excited reactive configuration of the $\pi$-complex (Scheme 1).

The high reactivity of the ortho haloanisoles must arise from a special effect of the methoxy substituent. An attractive explanation for the high reactivity of the ortho radical cations toward $\mathrm{CH}_{3} \mathrm{NH}_{2}$ is a stabilization of the reactive ipso adduct by a hydrogen bond between the ammonium group and the neighbouring methoxy substituent as indicated in Scheme 4. The special stability of this ipso adduct favors its formation either directly during the addition step or by the "ring walk" rearrangement of the amine in the isomeric addition complexes. In contrast, a stabilization of the adduct at the ortho position of the methoxy substituent hinders the formation of the ipso complexes $\mathbf{D}$ in the case of the meta and para haloanisole radical cations. Since formation of $\mathbf{D}$ is obligatory for the loss of the halogen atom the rates of substitution decrease.

Another special feature of the reactions of the chloroanisole radical cations with methylamine is the formation of substitution products by elimination of $\mathrm{HCl}$. The loss of $\mathrm{HCl}$ during substitution of halogenated benzene radical cations by $\mathrm{NH}_{3}$ and other nucleophiles was also observed by Baumgärtel and Brutschy [18] during a study of intramolecular reactions in van der Waals' clusters of halobenzenes and $\mathrm{NH}_{3}$ subsequent to resonant two-photon ionization. In the present case the structure of the product ions arising from the
Table 6

Reaction efficiencies (eff.) and reaction enthalpics, $\Delta H_{\mathrm{f}}$, of rcactions (3a) and (3b)

\begin{tabular}{|c|c|c|c|c|}
\hline \multirow[t]{2}{*}{ Reactant ion } & \multicolumn{2}{|c|}{$\begin{array}{l}\text { Elimination of } X \\
\text { reaction }(3 a)\end{array}$} & \multicolumn{2}{|c|}{$\begin{array}{l}\text { Elimination of } \mathrm{HX}, \\
\text { reaction }(3 \mathrm{~b})\end{array}$} \\
\hline & $\begin{array}{l}\Delta H_{\mathrm{r}} \\
{\left[\mathrm{kJ} \mathrm{mol}^{-1}\right]}\end{array}$ & $\begin{array}{l}\text { Eff. } \\
(\%)\end{array}$ & $\begin{array}{l}\Delta H_{\mathrm{r}} \\
{\left[\mathrm{kJ} \mathrm{mol}^{-1}\right]}\end{array}$ & $\begin{array}{l}\text { Eff. } \\
(\%)\end{array}$ \\
\hline$o$-Chloroanisole & -28 & 17 & -152 & 1.7 \\
\hline$p$-Chloroanisole & $+39^{b}$ & 0.1 & $-85^{b}$ & 1.2 \\
\hline o-Bromoanisole & $-98^{c}$ & 24 & $-157^{c}$ & not \\
\hline p-Bromoanisole & -71 & 4.3 & -130 & observed \\
\hline
\end{tabular}

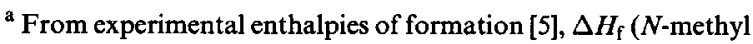
anisidine ion) are unknown and were estimated from $\Delta H_{\mathrm{f}}$ of anisidine radical cations and of protonated anisidines [5]. The effects of $N$-methyl groups were approximated by using the $\Delta H_{\mathrm{f}}$ difference of the corresponding aniline ions and $N$-methyl aniline ions [5]. ${ }^{b}$ The literature value of the $I E$ (para-chloroanisole) of $7.8 \mathrm{eV}$ [5] is very likely too low, yielding a small $\Delta H_{\mathrm{f}}$ of the radical cation and a too positive value of $\Delta H_{\mathrm{r}}{ }^{\mathrm{c}} \Delta H_{\mathrm{f}}$ (orthobromoanisole radical cation) estimated using $\Delta H_{\mathrm{f}}$ (arthobromoanisole) $=42 \mathrm{~kJ} \mathrm{~mol}^{-1}$ and $I E \approx 8.4 \mathrm{eV}$.

loss of $\mathrm{HCl}$ here was determined by CA mass spectrometry which verifies an ipso substitution process also for the elimination of $\mathrm{HCl}$ from the addition intermediate. The $\mathrm{H}$ atom climinated with $\mathrm{HCl}$ certainly originates from the $\mathrm{NH}_{2}$ group of the methylamine as shown by the reactions of the radical cations of deuterated haloanisoles. The labelling experiments exclude also any exchange of hydrogen atoms of the amine and at the aromatic ring. Thus, an intermediate arising by hydrogen abstraction from the amine by the radical site in the collision complex $\mathbf{C}$ or in the adduct $\mathbf{D}$ (Scheme 3) is excluded. More likely, the hydrogen atom migrates directly from the amino group to the leaving chloro substituent.

The values of the respective $\Delta H_{\mathrm{f}}$ in Table 6 show that the elimination of $\mathrm{HCl}$ is always favored energetically over the loss of the halogen atom. However, although the bromoarene radical cations are substituted with almost identical efficiencies to those of the corresponding chloroderivatives, the loss of $\mathrm{HBr}$ is not observed. Furthermore, the elimination of $\mathrm{HCl}$ occurs only if the loss of $\mathrm{Cl}$ is slow, and 
thus has been observed before during the reactions of the unreactive radical cations of chloroiodobenzenes [1] with $\mathrm{NH}_{3}$ and $\mathrm{CH}_{3} \mathrm{NH}_{2}$. Clearly, these competing substitution reactions by loss of $\mathrm{Cl}$ or $\mathrm{HCl}$ lack any correlation with the reaction enthalpy, and obviously in both reactions the rate determining reaction step is not bond breaking to the halosubstituent.

The elimination of $\mathrm{HCl}$ during the substitution reaction of haloarene radical cations with $\mathrm{NH}_{3}$ or amines must involve an additional slow reaction step, so that $\mathrm{HCl}$ elimination cannot compete with $\mathrm{Cl}$ elimination in fast substitution reactions (reaction efficiency $>10 \%$ ). Furthermore, the occurrence of $\mathrm{HCl}$ elimination and the branching between loss of $\mathrm{Cl}$ and $\mathrm{HCl}$ depend on the particular structure of the haloarene radical cation. For example, in the series of dihalobenzenes the 1-chloro-2iodobenzene radical cations react about five times faster with $\mathrm{NH}_{3}$ than the para dichlorobenzene radical cations, but only the former ions react by loss of $\mathrm{HCl}$ [1]. In addition, the reaction of 1-chloro-2-iodobenzene radical cations with $\mathrm{NH}_{3}$ is faster by a factor $>300$ than that of the 1-chloro-4-iodo isomer, but the ratio for the loss of $\mathrm{Cl}, \mathrm{HCl}$, and $\mathrm{I}^{\prime}$ is almost identical for both radical cations [1]. Obviously, the rate determining step for both substitution reactions precedes that point on the reaction coordinate where branching between loss of $\mathrm{X}$ and HX takes place. The kinetic behavior of the chloroanisole radical cations during the reactions with $\mathrm{CH}_{3} \mathrm{NH}_{2}$ implies that the rate determining step is the addition step $\mathbf{C} \rightarrow \mathbf{D}$ (Scheme 3). Therefore, the competition between substitution by loss of $\mathrm{Cl}$ and $\mathrm{HCl}$ takes place in an intermediate chemically activated by the preceding addition step and can be described in analogy to unimolecular decompositions of excited ions by competition between direct bond cleavage and rearrangement processes. Thus, the ions with less internal energy prefer a slow decom- position by energetically favorable rearrangements, in the case discussed the elimination of $\mathrm{HCl}$, while strongly excited ions decompose rapidly by entropically favored direct bond cleavages, i.e. the loss of $\mathrm{Cl}$. This means that branching between the two substitution routes of the haloarene radical cations is controlled by the activation energy and exothermicity of the dissociation steps for the loss of $\mathrm{Cl}$ and $\mathrm{HCl}$ and by the extent of a chemical activation by preceding reaction steps. This causes a complicated interplay of energetic and entropic effects which is difficult to untangle experimentally.

The reactions of $\left(\mathrm{CH}_{3}\right)_{2} \mathrm{NH}^{+}$radical cations with neutral bromo- and chloroanisoles occur predominantly by substitution of the halogen atom (reaction (4a)) and by charge transfer (reaction (4c)). The loss of bromine or chlorine from the neutral haloanisoles by reaction with $\left(\mathrm{CH}_{3}\right)_{2} \mathrm{NH}^{+}$exhibits the same ortho $\gg$ para $>$ meta reactivity order as the reactions with chloroiodobenzenes [2]. This indicates analogous reaction mechanisms; a detailed discussion of the mechanisms of the substitutions of neutral halobenzenes by amine radical cations has been published [2]. However, the reaction of $\left(\mathrm{CH}_{3}\right)_{2} \mathrm{NH}^{+}$with chloroanisoles exhibits some additional features, not observed for dihalobenzenes and for bromoanisoles (Table 3). Substitution by elimination of $\mathrm{HCl}$ (reaction (4b)) is observed for meta- and parachloroanisole, but not for ortho-chloroanisole. In the latter case the loss of $\mathrm{Cl}$ is quite efficient, and this is a further example of the rule that elimination of $\mathrm{HCl}$ competes only with slow losses of $\mathrm{Cl}$ in spite of the much larger reaction exothermicity of $\mathrm{HCl}$ loss. The parallel behaviour with respect to the elimination of $\mathrm{HCl}$ in nucleophilic substitution of chloroanisole radical cations by $\mathrm{CH}_{3} \mathrm{NH}_{2}$ and electrophilic substitution of neutral chloroanisoles by $\left(\mathrm{CH}_{3}\right)_{2} \mathrm{NH}^{+}$radical cation corroborates analogous intermediates in both processes which are responsible for the branching 
between loss of $\mathrm{Cl}$ and of $\mathrm{HCl}$. This intermediate can only be the $\sigma$-complex $\mathbf{D}$ generated in the addition step. Thus, these results give additional credit to the $\mathrm{HCl}$ mechanism discussed above. Note, however, that for nucleophilic and electrophilic substitutions different amines were used. The internal energy of complex $\mathbf{D}$ is therefore different for the two processes. The transfer of a proton from the $\left(\mathrm{CH}_{3}\right)_{2} \mathrm{NH}^{+}$to chloroanisoles (reaction (4d)) is certainly induced by the enhanced proton affinity of the chloroanisoles. The proton affinities of the haloanisoles are not known and it remains ambiguous why $\mathrm{H}^{+}$transfer is observed for chloroanisoles but not for bromoanisoles. The formation of $\left(\mathrm{CH}_{3}\right)_{2} \mathrm{NH}_{2}^{+}$ (reaction (4e)) corresponds formally to $\mathrm{H}$ abstraction from chloroanisole. The reaction $\left(\mathrm{CH}_{3}\right)_{2} \mathrm{NH}^{+}+\mathrm{C}_{6} \mathrm{H}_{5} \mathrm{OCH}_{3} \rightarrow\left(\mathrm{CH}_{3}\right)_{2} \mathrm{NH}_{2}^{+}+$ $\mathrm{C}_{6} \mathrm{H}_{5} \mathrm{OCH}_{2}$ is exothermic by $-74 \mathrm{~kJ} \mathrm{~mol}^{-1}$ and by analogy a $\mathrm{H}$ atom transfer should be exothermic for all bromo- and chloroanisoles. However, the reaction is only observed for the meta isomer, and the $\mathrm{H}$ transfer very likely occurs by a rather complex and still unknown mechanism.

\section{Acknowledgement}

The FT-ICR spectrometer used in this study has been granted by the Deutsche Forschungsgemeinschaft. The financial assistance of the DFG and additional assistance by the Fonds der Chemischen Industrie is gratefully acknowledged.

\section{References}

[1] D. Thölmann and H.Fr. Grützmacher, J. Am. Chem. Soc., 113 (1991) 3281.
[2] D. Thölmann and H.Fr. Grützmacher, Int. J. Mass Spectrom. Ion Processes, 117 (1992) 415,

[3] J. March, Advanced Organic Chemistry, 3rd edn., Wiley, New York, 1985.

[4] (a) A. Pross and S.S. Shaik, Acc. Chem. Res., 16 (1983) 363. (b) S.S. Shaik, Prog. Phys. Org. Chem., 15 (1985) 197. (c) S.S. Shaik and A. Pross, J. Am. Chem. Soc., 111 (1989) 3537. (d) S.S. Shaik, Acta Chem. Scand., 44 (1990) 205. (e) S.S. Shaik and E. Canadell, J. Am. Chem. Soc., 112 (1990) 1446.

[5] S.G. Lias, J.F. Liebman, J.L. Holmes, R.D. Levin and W.G. Mallard, J. Phys. Chem. Ref. Data, 17 (1988) Suppl. 1.

[6] F. Drahowzal and D. Klamann, Monatsh. Chem., 82 (1951) 588.

[7] L.-F. Tietze and T. Eicher, Reaktionen und Synthesen, Thieme-Verlag: Stuttgart, 1981.

[8] M. Allemann, Hp. Kellerhals and K.P. Wanczek, Int. J. Mass Spectrom. Ion Phys., 46 (1983) 139.

[9] P. Kofel, M. Allemann, Hp. Kellerhals and K.P. Wanczek, Int. J. Mass Spectrom. Ion Proc., 65 (1985) 97.

[10] D. Smith and N.G. Adams, Int. J. Mass Spectrom. Ion Phys., 23 (1977) 123.

[11] N.G. Adams, D. Smith and J.F. Paulson, J. Chem. Phys., 72 (1980) 288.

[12] T.B. McMahon and J.L. Beauchamp, J. Phys. Chem., 81 (1977) 593.

[13] J.E. Bartmess and R.M. Georgiadis, Vacuum, 33 (1983) 149.

[14] A.J. Noest and C.W.F. Kort, Comput. Chem., 6 (1982) 115.

[15] P. Kofel, Dissertation, Bremen (1987).

[16] D. Thölmann, R. Wolf and H.-Fr. Grützmacher, Adv. Mass Spectrom., 11A (1989)556.

[17] (a) C.D. Hanson, E.L. Kerley, M.E. Castro and D.H. Russel, Anal. Chem., 61 (1989) 2040. (b) M. Wang and A.G. Marshall, Anal. Chem., 62 (1990) 515. (c) C.D. Hanson, M.E. Castro, E.L. Kerley and D.H. Russel, Anal. Chem., 62 (1990) 520. (d) A.R. Katrizky, C.H. Watson, Z. Dega-Szafran and J.R. Eyler, J. Am. Chem. Soc., 112 (1990) 2471. (e) P.B. Grosshans and A.G. Marshall, Int. J. Mass Spectrom Ion Processes, 115 (1992) 1 .

[18] (a) B. Brutschy, J. Phys. Chem., 94 (1990) 8637. (b) J. Eggert, C. Janes, B. Wassermann, B. Brutschy and H. Baumgärtel, Ber. Bunsenges. Phys. Chem., 94 (1990) 1282. (c) B. Brutschy, J. Eggert, C. Janes and H. Baumgärtel, J. Phys. Chem., 95 (1991) 5041. (d) C. Riehn, J. Avdiew, J. Eggert, B. Wassermann, B. Brutschy and H. Baumgärtel, J. Mol. Struct., 249 (1991) 33. (e) C. Riehn, C. Lahmann and B. Brutschy, J. Phys. Chem., 96 (1992) 3626. 